\title{
SOA-based multiwavelength fiber laser assisted by intensity dependent transmission mechanism
}

\begin{abstract}
We investigate an intensity influence towards the flatness of multiwavelength fiber laser (MWFL) based on intensity dependent transmission (IDT) mechanism. The intensity is varied by changing semiconductor optical amplifier (SOA) current and throughput port ratio. Owing to the IDT mechanism, the multiwavelength flatness is degraded with the increment of SOA current. The change of throughput port ratio of optical splitter from $10 \%$ to $90 \%$ has also affected a worse multiwavelength flatness. The flattest multiwavelength spectrum is achieved at SOA current and throughput port of $150 \mathrm{~mA}$ and $10 \%$, respectively, with the lasing lines are counted up to 300 channels within $3 \mathrm{~dB}$ uniformity.
\end{abstract}

Keyword: Multiwavelength fiber laser; Lyot filter; Intensity dependent transmission; Semiconductor optical amplifier 